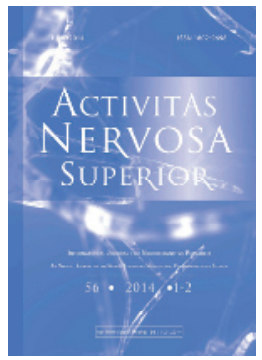

\title{
SPLITTING OF THE MIND AND UNCONSCIOUS DYNAMICS
}

\author{
Terezie Jiraskova* \\ Department of Psychiatry, First Faculty of Medicine, Charles University, Prague, Czech Republic
}

\begin{abstract}
Freud and Breuer proposed the concept of splitting of the mind and described it in various clinical cases and the concept was later developed in studies by Klein, Kohut, Kernberg and others. These basic clinical findings were also confirmed by later studies using Rorschach projective test documenting that splitting in mental structures may be observed in phantasies and associations reflecting cognitive and affective contents related to conflicting interpretations of objects, other persons and the self. Altogether these data indicate that splitting represents a specific form of dissociation resulting from a conflict that leads to splitting of the ego and other parts of the psychic apparatus into separated subsystems. In this context, splitting and dissociation do not mean different terms even they are used in different contexts for description of specific conditions that may occur in various mental disorders.
\end{abstract}

Key words: Dissociation; Splitting; Unconscious Dynamics; Mental Activity

\section{INTRODUCTION}

Sigmund Freud proposed the concept of splitting based on observations of phenomena related to hysteria and hypnosis that led to mental disintegration (Freud \& Breuer, 1895). They observed that some events in childhood may create more or less severe symptoms which tend to persist and may lead to hysteria (Freud \& Breuer, 1895, p. 7). Freud and Breuer observed that hysterical symptoms tend to disappear when "hidden" traumatic memories were recognized in memory of a patient and succesfully described (Freud \& Breuer, 1895). At the same time similar findings reported also Delboeuf and Binet, who shown that when a subject goes back into the state in which his/her troubles first appeared and uses words to describe these experiences, then it significantly improves his/her mental state. In addition they also found that using hypnosis for this purpose may be particularly efficient (Ellenberger, 1970). Similar data also reported Janet in his interesting study on mental automatisms (Janet, 1889; Ellenberger, 1970).

In this context, Breurer and Freud thought that a reason for this mental disintegration or "splitting" is caused by a mechanism of psychological defense that comes into operation when an instance of incompatibility arises in ideational life between a particular idea and the 'ego' (Freud \& Breuer, 1895, p. 446). Breuer and Freud explained their view differently than Janet and thought that the splitting of consciousness does not occur because a patient is

${ }^{*}$ Correspondence to: Terezie Jiraskova, e-mail: tjirasko@gmail.com

Received May 22, 2013; accepted June 22, 2014; Act Nerv Super 56(1-2), 24-27; ISSN-1802-9698 
weak-minded as Janet proposed in his concept of psychasthenia, but most likely due to mental incompatibility of certain ideas and affects that may create intrapsychic conflict (Freud \& Breuer, 1895, p. 208).

To characterize these cases Freud defined splitting of consciousness as a process of oscillation between two different psychical complexes, which become conscious and unconscious in alteration (Freud, 1912, p. 2850). Later Freud (1940) extended this idea and described splitting of the ego into coexisting parts, which in most extreme forms occurs in psychoses, where it leads to deep ego distortions. As Freud (1940) suggested splitting of the ego is characterized by two contrary and independent attitudes, where one of these conflicting attitudes belongs to the ego and the contrary one is repressed.

\section{PSYCHOANALYTIC VIEW OF SPLITTING AND DISSOCIATION}

Freud followed basic Janet's approach of splitting of the mind and dissociation of the personality for understanding of abnormal states of consciousness but mainly he thought that basic factor of splitting is the intrapsychic conflict and not constitutional weakness (psychasthenia) as Janet postulated (Ellenberger, 1970). Developmental concept of splitting was elaborated in details by Melanie Klein (1940, 1950, 1952), who proposed that children adopt splitting as one of the several psychic defense mechanisms to protect their ego against anxiety. The splitting is mainly directed to maintain basic separation between gratifying good objects and frustrating bad objects and according to Klein, children learn this mechanism during first three or four months of their life (Klein, 1940, 1950). When later a child becomes aware that its mother includes both good and bad qualities in one, children ego will become much more integrated, but it is still in the conflict between opposed drives, which may be resolved by a mechanism of repression (Klein 1940, 1950). In general, splitting can either have positive or negative influence on the child's personal growth. In a positive way, splitting enables to understand and accept positive and negative aspects of themselves and others, but excessive and rigid splitting may lead to pathological repression, and insufficiency to recognize "good me" and "bad me", which represents a typical manifestation of the pathological repression (Klein, 1940, 1950).

Following previous concepts, also Heinz Kohut described the process of splitting (1966, 1971) and proposed that splitting is based on a relatively weak differentiation of the self and others. Children are usually driven by a fantasied sense of themselves as omnipotent and omniscient (grandiose self), but on the other hand, children provide a hugh greatness to their parents (parent imago) that produces split-off parts of the personality (Kohut, 1966; Westen, 1991). In the similar context, Otto Kernberg (1975) also conceptualized the splitting phenomena and described different levels of personality organization that may be observed in clinical examinations of adolescents and adults (Westen, 1991). Highest forms of splitting have chronically psychotic people, whose ability to test reality and form meaningful relationships is very low. On the other hand, individuals with borderline personality disorder have a weak sense of identity and cognitively immature representations of the self and others, which is linked to a tendency to idealize, devaluate and also manipulate people (Westen, 1991). On the contrary, neurotic conflicts are typically related to disturbed representations of the self and others, and disrupted ability to invest into relationships and values (Kernberg, 1975; Westen, 1991). In this context, Kernberg also proposed a concept of the splitting of representations to characterize borderline patients in whom the self and others are viewed at a given time as either all good or all bad without anything between this good-bad dichotomy (Westen, 1991). This splitting leads to disability to integrate positive and negative aspects of the self and others into coherent perceptions and produces "contradictory view" that things or persons are black or white, good or bad etc., and something between these polarities seems to be impossible (Kernberg, 1975; Fuchs, 2007). 
These contradictory representations of the self create disturbances of the mind. This splitting is based on a lack of higher-level of self-observational processes by which a person normally monitors ongoing thoughts for coherence and accuracy (Kernberg, 1975, Fuchs, 2007). As a consequence of some concepts and findings proposed by Kernberg, the defense mechanism of splitting has attained a special importance through conceptualization of borderline personality organization that had a significant influence on psychoanalytic understanding of splitting phenomena (Kernberg, 1975; Marmar \& Horowitz, 1986). In this context, Kernberg (1975) defined splitting as an essential defensive operation of the borderline personality organization, where this splitting of mind manifests not only as affective states of the ego, but also as a split of the self and object images. Kernberg (1975) proposed that the borderline structure is characterized by predomination of the bad self and also object representations predominate over the good, because of limited positive self and object representations, which leads to a predominance of hostile and aggressive internalized objects (Kernberg, 1975; Siegel, 2006). Because of that splitting is used as a defensive action of idealization and devaluation, which in real life situations are experienced and remembered in the extreme as black or white (Glassman, 1986, Siegel, 2006). Although this defense mechanism of splitting manifests in all individuals under certain circumstances, when it occurs too frequently, it seriously disturbs integrative functions and "good and bad", "self and object", representations continue to exist in relatively isolated states (Glassman, 1986; Siegel, 2006; Fuchs, 2007).

\section{MANIFESTATIONS OF SPLITTING IN RORSCHACH PROJECTIVE TEST}

According to several reported data, content analyses of Rorschach responses enables detailed descriptions of various levels of splitting and other defensive operations that are usually observed in clinical case studies. These data indicate that Rorschach projective method enables to describe specific details and also scoring that is useful for statistical research (Sugarman, 1980; Grala, 1980; Smith, 1980; Lerner \& Lerner, 1980; Cooper, Perry, \& Arnow, 1988). Based on this analysis Sugarman (1980) and Grala (1980) reported the frequent presence of certain specific forms in Rorschach associations in individuals with borderline personality disorder that seem to be in agreement with Kernberg's clinical observations suggesting disturbed reality testing (Kernberg, 1975; Cooper, Perry, \& Arnow, 1988). Similarly, Singer and Larson (1981) reported that borderline patients show a significant deterioration of quality form and level of integration on each Rorschach card, and also increased level of fabulized combinations (Singer \& Larson, 1981) and confabulations (Sugarman, 1980).

These basic findings were also confirmed by later studies documenting that splitting in mental structures may be observed in phantasies and associations reflecting cognitive and affective contents related to conflicting interpretations of objects, other persons and the self (Berg, 1990; Blais et al., 1999; Leichsenring, 1999; Fowler et al., 2000).

\section{CONCLUSIONS}

According to recent findings, splitting represents a specific form of dissociation resulting from a conflict that leads to disintegration of the ego or splitting of its objects reflecting intrapsychic process of dividing mental capacities in the psychic apparatus into separated subsystems. These subsystems may be described by using a topography based on unconscious, preconscious and conscious processes, and also by a topography reflecting structure of agencies such as id, ego and superego. In this context, splitting and dissociation do not mean different terms even they are used in different contexts for description of specific conditions that may occur in various mental disorders. 


\section{ACKNOWLEDGEMENT}

This work was supported by the Scientific Research Project SVV provided by Charles University.

\section{REFERENCES}

Berg, J.L. (1990). Differentiating ego functions of borderline and narcissistic personalities. Journal of Personality Assessment, 55, 537-48.

Blais, M.A., Hilsenroth, M.J., Fowler, J.C., \& Conboy, C.A. (1999). A Rorschach exploration of the DSMIV Borderline Personality Disorder. Journal of Clinical Psychology, 55, 563-72.

Cooper, S., Perry, J., \& Arnow, D. (1988). An empirical approach to the study of defense mechanisms: I. Reliability and preliminary validity of the Rorschach defense scales. Journal of Personality Assessment, $52,187-203$.

Fowler, J.C., Hilsenroth, M.J., \& Nolan, E. (2000). Exploring the inner world of self-mutilating borderline patients: a Rorschach investigation. Bulletin of the Menninger Clinic, 64, 365-85.

Freud, S. \& Breuer, J. (1895). Studies on hysteria. The Standard Edition of the Complete Psychological works of Sigmund Freud, 2: 48-106.

Freud, S. (1912). A note on the unconscious in psychoanalysis. The Standard Edition of the Complete Psychological works of Sigmund Freud, 12.

Freud, S. (1940). Splitting of the ego in the process of defence. The Standard Edition of the Complete Psychological works of Sigmund Freud, 23: 271-278.

Fuchs, T. (2007). Psychopathology, Fragmented Selves: Temporality and Identity in Borderline personality Disorder. Psychopathology, 40, 379-387.

Glassman, M. B. (1986). Splitting: Further contributions to the development of a measure, Journal of Clinical Psychology, 42(6).

Grala, C. (1980). The concept of splitting and its manifestations on the Rorschach test. Bulletin of the Menninger Clinic, 44, 253-271.

Janet, P. (1989). L'Automatisme psychologique, Félix Alcan, Paris.

Kernberg, O.F. (1975). Borderline Conditions and Pathological Narcissism. New York, A Jasona Aronson Book.

Klein, M. (1940). Mourning and its Relation to Manic-Depressive states. International Journal of PsychoAnalysis, 21, 125-153.

Klein, M. (1950). On the Criteria for the Termination of an Analysis. International Journal of PsychoAnalysis, 31, 204.

Klein, M. (1952). The mutual influences in the development of ego and id. Psychoanalytic Study of the Child, 7, 51-53.

Kohut, H. (1966). Forms and transformations of narcissism, Journal of American Pychoanalytic Association, 14. $243-272$

Kohut, H. (1971). The analysis of the self. New York: International Universities Press.

Leichsenring, F. (1999). Splitting: an empirical study. Bulletin of the Menninger Clinic, 63, 520-37.

Marmar, CH. R. \& Horowitz M. J. (1986). Phenomenological Analysis of Splitting, Psychotherapy. Langley Porter Psychiatric Institute, 9, 21-29.

Lerner, P., \& Lerner, H. (1980). Rorschach assessment of primitive defenses in borderline personality structure. In: L. Kwawer, A. Sugarman, P. Lerner, \& H. Lerner (Eds.), Borderline phenomena and the Rorschach test (pp. 257-274). New York: International Universities Press.

Siegel, J. P. (2006). Dyadic Splitting in Partner Relational Disorders. Journal of Family Psychology, 20, 418422.

Singer, M.T., \& Larson., D.G. (1981). Borderline personality and the Rorschach test. Archives of General Psychiatry, 38, 693-698.

Smith, K. (1980). Object relations concepts as applied to borderline level of ego functioning. In: J. Kwawer, A. Sugarman, P. Lerner, \& H. Lerner (Eds.), Borderline phenomena and the Rorschach test (pp. 59-87). New York: International Universities Press.

Sugarman, A. (1980). The borderline personality organization as manifested on psychological tests. In: J. Kwawer, A. Sugarman, P. Lerner, \& H. Lerner (Eds.), Borderline phenomena and the Rorschach test (pp. 39-58). New York: International Universities Press.

Westen, D. (1991). Social Cognition and Object Relations. Psychological Bulletin, 3, 429-455. 